\title{
Erratum to: Automatic panorama with auto-focusing based on image fusion for microscopic imaging system
}

\author{
Hulya Dogan · Murat Ekinci
}

Published online: 5 December 2014

(c) Springer-Verlag London 2014

Erratum to: SIViP (2014) 8 (Suppl 1):S5-S20

DOI 10.1007/s11760-014-0717-5

In the original publication, the authors have made a typographical error in reference 20. The correct version of the reference should read as follows:

Piccinini, F., Bevilacqua, A., Lucarelli, E.: Automated image mosaics by non-automated light microscopes: the MicroMos software tool. J. Microsc. 252(3), 226-250 (2013).

The online version of the original article can be found under doi:10.1007/s11760-014-0717-5.

H. Dogan $(\varangle) \cdot$ M. Ekinci

Computer Engineering Department, Karadeniz Technical University, Trabzon, Turkey

e-mail: hulya@ktu.edu.tr

M. Ekinci

e-mail: ekinci@ktu.edu.tr 